\title{
Hojalata: Evaluación de su Comportamiento frente a la Corrosión en Medios Acuosos
}

\author{
José D. Culcasi ${ }^{1}$, Cecilia I. Elsner ${ }^{2}$ y Alejandro R. Di Sarli ${ }^{2}$ \\ (1) Universidad Nacional de La Plata, Facultad de Ingeniería, Laboratorio de Investigaciones de \\ Metalurgia Física (LIMF) "Ing. Gregorio Cusminski", Calle 48 y 116, B1900TAG La Plata-Argentina \\ (e-mail: jculcasi@ing.unlp.edu.ar) \\ (2) Centro de Investigación y Desarrollo en Tecnología de Pinturas-CIDEPINT (CIC-CONICET), \\ Av. 52 s/n, entre 121 y 122, B1900AYB La Plata-Argentina (e-mail: anelpire@cidepint.gov.ar)
}

Recibido Abr. 20, 2009; Aceptado Jun. 09, 2009; Versión Final recibida Jul. 07, 2009

\begin{abstract}
Resumen
Las primeras etapas del deterioro de chapas comerciales de hojalata expuestas a distintas soluciones salinas fueron estudiadas mediante técnicas electroquímicas y de análisis de superficie complementadas por microscopia óptica y electrónica de barrido. Sus resultados fueron analizados e interpretados utilizando modelos capaces de describir adecuadamente la degradación metálica de interfaces tan complejas como reactivas. Se concluyó que: 1) el deterioro de la superficie metálica ocurre mayormente durante las primeras 24 horas de inmersión, alcanzándose luego un comportamiento relativamente estable y reproducible con independencia del medio utilizado; 2) excepto en las soluciones "buffer" basadas en bórax o carbonato donde los escasos productos de corrosión aportaron un efecto protector, en los restantes medios tales productos fueron, en general variantes no protectoras de un oxihidróxido de hierro; y 3) estos resultados coinciden con las velocidades de corrosión determinadas electroquímicamente $\mathrm{y}$, por ende, con el lapso de vida útil del recubrimiento.
\end{abstract}

Palabras clave: corrosión, espectroscopia de impedancia electroquímica, polarización, difracción de rayos $X$, microscopia electrónica de barrido

\section{Tinplate: Evaluation of its Corrosion Behavior in Aqueous Media}

\begin{abstract}
The first deterioration steps suffered by commercially available tinplate sheets exposed to different saline solutions were studied using electrochemical and surface analysis techniques, as well as optical and electronic scanning microscopy. Their results were analyzed and interpreted utilizing models able to adequately describe the degradation of those as complex as reactive metallic interfaces. It was concluded that: 1) independently of the medium, the main degradation of the metallic surface takes place within the first $24 \mathrm{~h}$ immersion, but then its behavior is relatively stable and reproducible; 2) except in the buffer solutions based on borax or carbonate where the scarce corrosion products provided a protective effect, in the other electrolyte medium such products were, in general, a variety of non-protective iron oxyhydroxides; and 3) these results are in agreement with the electrochemically determined corrosion rates and, therefore, with the coating useful life.
\end{abstract}

Keywords: corrosion, electrochemical impedance spectroscopy, polarization, $X$ rays difraction, scanning electronic microscopy 


\section{INTRODUCCIÓN}

La hojalata es un material heterogéneo con una estructura estratificada que, básicamente, consiste de una delgada chapa de acero recubierta en ambas caras con estaño y, usualmente, laqueada. A pesar del creciente uso industrial de latas fabricadas con nuevos materiales alternativos tales como aluminio y acero cromado, el estaño continúa siendo utilizado en más del $80 \%$ de los casos.

Los principales factores que afectan la degradación de la hojalata son: 1) la composición del acero base y, en particular, su contenido de algunos elementos tales como azufre y fósforo; 2) la aleación $\mathrm{Fe} / \mathrm{Sn}$ en la interfaz, especialmente su forma de cristalización y continuidad (Zumelzu y Cabezas, 1996); 3) la capa de estaño libre, su espesor, uniformidad, forma de cristalización, continuidad y tamaño de grano (cuanto menor es este, menor la resistencia a la corrosión (Palmieri et al., 2004); y 4) el pre-tratamiento de pasivación y posterior aplicación de un recubrimiento orgánico (Doherty y Sykes, 2008). Por otra parte, las características del producto en contacto constituyen otro factor importante en la degradación de la hojalata. Entre ellas, la acidez y el tipo de ácido que la provoca son, tal vez, las más significativas debido a su agresividad. Asimismo, la velocidad del proceso corrosivo es afectada por la viscosidad del producto (si ésta es alta, dificulta la difusión iónica y con ello le pone un límite a aquélla); por su parte, la presencia de oxígeno y/u otras sustancias oxidantes, de complejantes como polifosfatos o taninos y la de nitratos o azufre influyen negativamente ya que lo aceleran (Larburu, 1996; Zumelzu y Cabezas, 2001; Huang et al., 2006; Toŝković et al., 2002).

Por otra parte, la corrosión externa de envases de hojalata que contienen productos alimenticios, aunque menos frecuente y comparativamente menos peligrosa que la corrosión interna, es otro factor que merece ser investigado ya que los consumidores exigen no sólo productos de calidad sino también envases con buena apariencia (Montanari et al., 2000).

Con el fin de estabilizar la superficie estañada, es importante aplicar un tratamiento de pasivación durante su fabricación y antes del laqueado. El propósito general de este tratamiento es: 1) prevenir el crecimiento de óxido de estaño sobre la superficie porque, si este es excesivo, puede causar decoloración durante un prolongado almacenamiento y/o los procesos de horneado asociados con el laqueado y la impresión; 2) evitar la aparición de manchas causadas por derivados del azufre contenido en ciertos alimentos enlatados; 3) mejorar la adhesión de la laca al sustrato metálico (Barilli et. al., 2003); y 4) mejorar la resistencia a la corrosión después del laqueado (Reinprayoon et al., 1998; Calderón y Buitrago, 2007).

El tratamiento de pasivación de la hojalata con dicromato fue el elegido a lo largo de más de 50 años. El fundamento, provee excelente protección contra la corrosión, muy buena adhesión a la película de laca e imparte buena resistencia a la corrosión provocada por los sulfuros provenientes de ciertos alimentos (Bastidas et al., 1997; Popova et al., 1990). Sin embargo, por más de 20 años se ha reconocido que los cromatos son altamente tóxicos y carcinogénicos. Las crecientes demandas ambientales y el cuidado de la salud pública (Blunden y Wallace, 2003) han obligado a aceptar que el uso de tales productos sea cada vez más restringido y, en un futuro próximo, totalmente prohibido, particularmente los que contienen $\mathrm{Cr}(\mathrm{VI})$. Consecuentemente, los riesgos ambientales y para la salud pública hacen necesario introducir profundos cambios en la formulación de tratamientos de pasivación dirigidos a la adopción de otros libres de cromo. Estos últimos deberán proveer criterios de performance equivalentes a los comerciales basados en sales de $\mathrm{Cr}(\mathrm{VI})$ y ser aplicables en líneas de producción industrial similares a las utilizadas con los tratamientos convencionales (Mora et al., 2004).

El objetivo del presente trabajo fue estudiar las primeras etapas del deterioro de chapas de hojalata desnuda de origen comercial expuestas a soluciones que simulan el medio líquido generado por diferentes productos. Para ello, se las puso en contacto con soluciones de $\mathrm{NaCl}, \mathrm{Nal}$ o $\mathrm{NaBr}$ a distinto $\mathrm{pH}$ o con un "buffer" cítrico/citrato, carbonato/bicarbonato o bórico/borato del mismo catión. El comportamiento de las muestras fue estudiado empleando técnicas electroquímicas de corriente continua y alterna, complementadas por microscopia óptica y electrónica de barrido y técnicas de análisis de superficie (EDXS, XPS, XRD). 


\section{METODOLOGÍA}

Chapas de hojalata desnuda comercialmente disponibles en el mercado fueron analizadas empleando diversas técnicas a fin de caracterizar la morfología y composición de la superficie metálica y su comportamiento electroquímico. En el primer caso fue utilizada microscopia electrónica de barrido (SEM), espectroscopia de energía dispersiva de rayos $X$ (EDXS), espectroscopia fotoelectrónica de rayos X (XPS) y difracción de rayos $X$ (XRD). Estos estudios fueron efectuados en las chapas testigo y luego de su exposición a diversas soluciones acuosas. Los estudios mediante SEM-EDXS fueron efectuados en un microscopio electrónico de barrido marca Philips SEM 505, con capacidad analítica a través del Sistema de Microsonda EDAX DX PRIME 10. Por su parte, los espectros XPS fueron tomados excitando con radiación de 1253,6eV (Mg Ka, no monocromático) y potencia de 200W, mediante un analizador de energías Hemisférico PHOIBOS 100 MCD, SPECS. Para la cuantificación fueron tenidas en cuenta las sensibilidades relativas y se supuso que los elementos se encuentran distribuidos homogéneamente en el volumen analizado. El estudio consistió en la obtención de un espectro amplio en energías de la superficie de cada muestra y uno angosto de los elementos de interés. La difracción de rayos $X$ fue llevada a cabo en un sistema automático de difracción Philips APD 1700 comandado con el software PW1897, utilizando radiación $\mathrm{K} \alpha$ de $\mathrm{Cu}$, con una tensión de $40 \mathrm{kV}$ y una corriente de $30 \mathrm{~mA}$. El barrido se efectuó en el modo $\theta-2 \theta$, entre 5 y $90^{\circ}$, con un paso de $0,02^{\circ}$ y un tiempo de $1 \mathrm{~s} /$ paso. El análisis de los difractogramas se efectuó con los software PC-Identify y X'Pert high Score de Philips, y la base de datos PC PDF win JCPDS-ICDD.

La celda electroquímica fue conformada de acuerdo a la clásica distribución de tres electrodos en la cual, el contraelectrodo era una malla de Pt-Rh, el de referencia un electrodo de Calomel Saturado $(E C S=+0,244 \mathrm{~V}$ vs. $E N H)$ y el electrodo de trabajo cada muestra de hojalata con un área geométrica expuesta variable según el tipo de ensayo. Las medidas fueron ejecutadas en soluciones $0,05 \mathrm{M}$ de $\mathrm{NaCl}(\mathrm{pH}=3,0 ; 5,9 ; 8,0)$, Nal $(\mathrm{pH}=3,0 ; 6,0 ; 8,0), \mathrm{NaBr}(\mathrm{pH}=3,0 ; 5,6 ; 8,0)$, "buffer" cítrico/citrato $(\mathrm{pH}$ $=4,3)$, carbonato/bicarbonato $(\mathrm{pH}=9,9)$ o bórico/borato $(\mathrm{pH}=9,3)$ con el mismo catión. De aquí en adelante, la nomenclatura utilizada para definir cada uno de los electrolitos es la siguiente: "buffers" Bo: bórico/borato; Co: carbonato/bicarbonato; Ci: cítrico/citrato; soluciones de halogenuros, $\mathrm{Cl}$ : $\mathrm{NaCl}$; $\mathrm{Br}: \mathrm{NaBr}$ e lo: Nal. Las curvas de polarización potenciodinámica fueron trazadas utilizando un potenciostato/ galvanostato PAR 273A, con una velocidad de barrido de $0,166 \mathrm{mV} . \mathrm{s}^{-1}$ y en el intervalo $\pm 0,250 \mathrm{~V}$ con respecto al potencial de circuito abierto (PCA). El electrodo de trabajo, área expuesta $1 \mathrm{~cm}^{2}$, era la muestra de hojalata ubicada en posición vertical.

Para las medidas de impedancia electroquímica (IE), dos tubos de acrílico fueron pegados sobre réplicas de cada chapa metálica (electrodo de trabajo) con un adhesivo adecuado; en cada uno de ellos, el área en contacto con el electrolito era $15,9 \mathrm{~cm}^{2}$. Una abertura en la parte superior permitía incorporar los tres electrodos. Los espectros de impedancia fueron obtenidos, en modo potenciostático y al PCA, usando un analizador de respuesta de frecuencia Solartron 1250 acoplado a una interfase electroquímica Solartron 1286 y a una PC controlados todos por el programa Zplot@. El intervalo de frecuencias barrido fue $5.10^{-3} \leq \mathrm{f}(\mathrm{Hz}) \leq 65.10^{3}$ y la amplitud de la señal sinusoidal $5 \mathrm{mV}$. Los datos colectados fueron analizados e interpretados en base al método de simulación y ajuste de los parámetros que componen circuitos eléctricos equivalentes desarrollado por Boukamp (Boukamp, 1989). Los ensayos electroquímicos fueron ejecutados al menos por duplicado y temperatura controlada $\left(22 \pm 2^{\circ} \mathrm{C}\right)$.

\section{RESULTADOS Y DISCUSIÓN}

\section{Caracterización superficial}

Los espectros EDXS de las chapas testigo mostraron, además de $\mathrm{Sn}$ y $\mathrm{Fe}$, la presencia de $\mathrm{C}, \mathrm{O}$ y $\mathrm{N}$. La relación atómica entre estos tres elementos fue de $22 \%$ de C, $50 \%$ de $\mathrm{N}$ y $28 \%$ de $\mathrm{O}$ (Fig. 1). Por su parte, los espectros XPS de las mismas chapas permitieron determinar que la composición química de su superficie contenía Sn (10\%), mayormente como Sn(IV), Cr (5,5\%), O (50\%), C (29\%), $\mathrm{N}(1 \%), \mathrm{Na}(4,2 \%)$ y $\mathrm{Ca}(0,3 \%)$. Del contenido total de cromo, $12 \%$ se encontraba como $\mathrm{Cr}^{+6}$ y el $88 \%$ restante como $\mathrm{Cr}^{+3}$ (Fig. 2). 


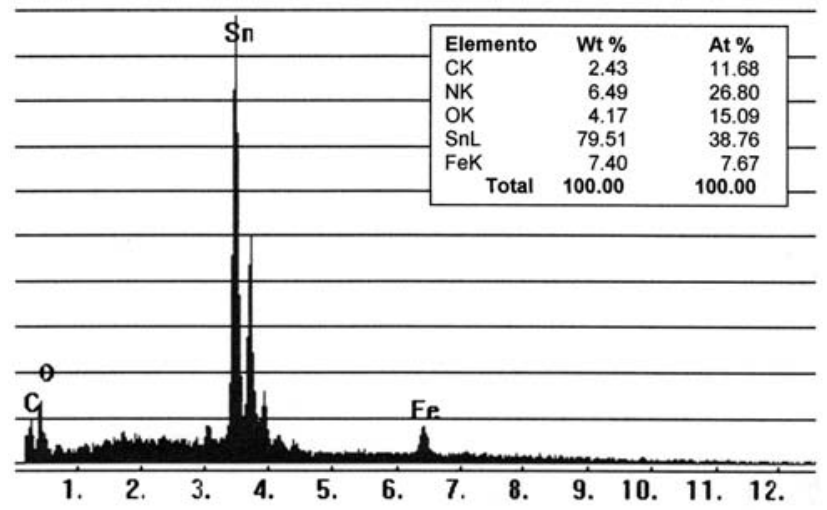

Fig. 1: Espectro EDXS de una chapa testigo.
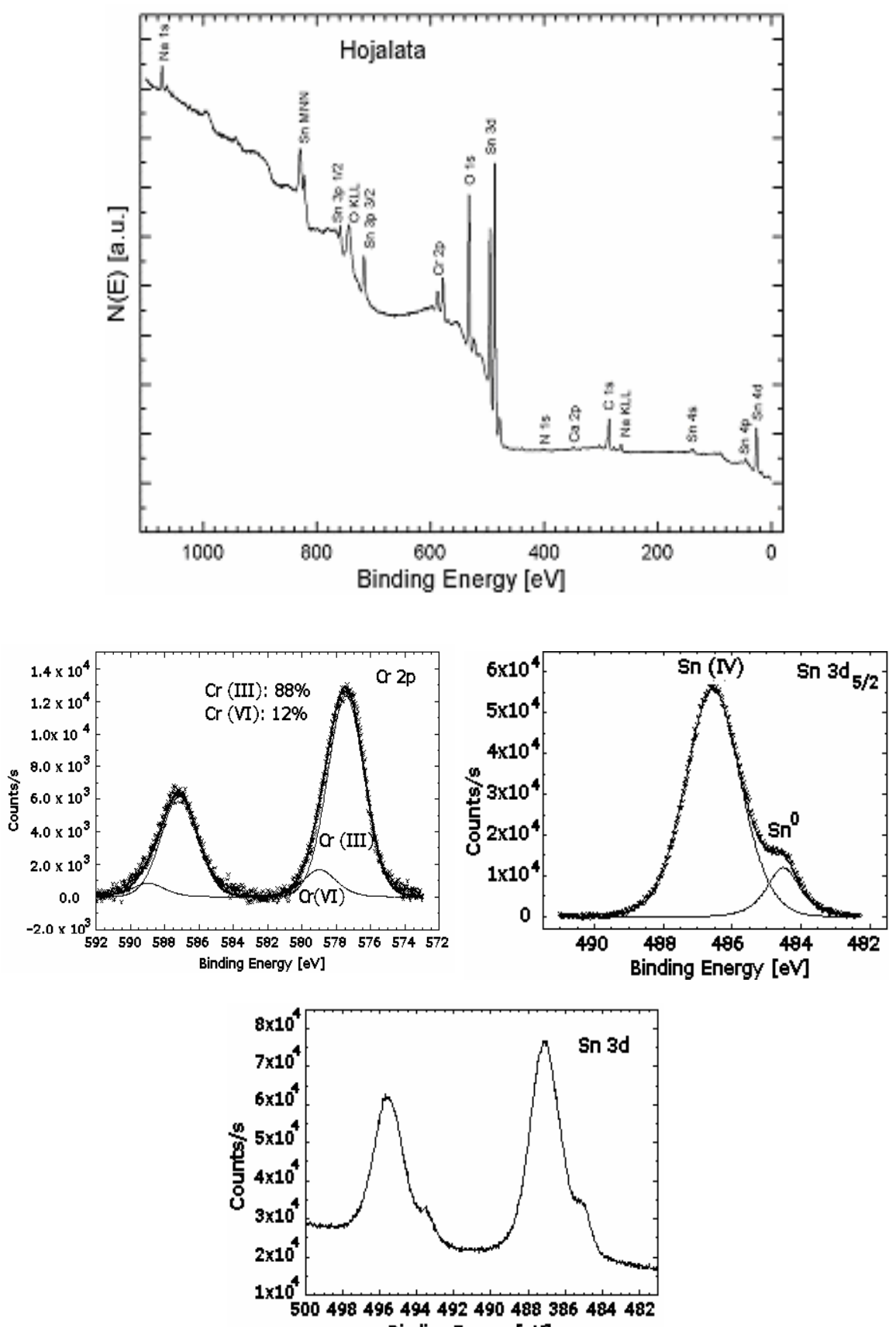

Binding Energy [oV]

Fig. 2: Espectros XPS de una chapa testigo. 
Los espectros de XRD de las chapas testigo mostraron que tanto el acero como el recubrimiento de Sn presentaban orientación cristalográfica preferencial. En el acero, la intensidad relativa de los picos de difracción correspondientes a los planos $\{211\}\left(82,416^{\circ}\right)$ superaba en más de un $300 \%$ a la de los planos $\{110\}\left(44,712^{\circ}\right)$ cuando, en una muestra sin textura, dicha intensidad relativa debería estar en el orden del $30 \%$. Por su lado, el Sn presentó una orientación preferencial según los planos $\{100\}$ (picos 200 , a $30,671^{\circ}$ y 400 , a $63,842^{\circ}$ ), en tanto que la intensidad relativa de los picos de difracción correspondientes a otras familias de planos resultó menor al $1 \%$. También fue detectada la presencia del intermetálico $\mathrm{FeSn}_{2}$ (Fig. 3a). En todos los casos estudiados, los espectros de XRD de las chapas sometidas a ensayos de impedancia electroquímica, Fig. 3b-g, mostraron una significativa reducción de los picos de difracción correspondientes a Sn, y una reducción menos acentuada de los picos del intermetálico $\mathrm{FeSn}_{2}$.

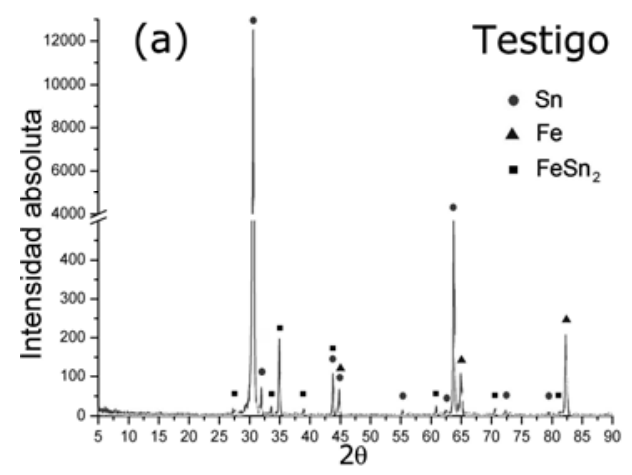

(b)
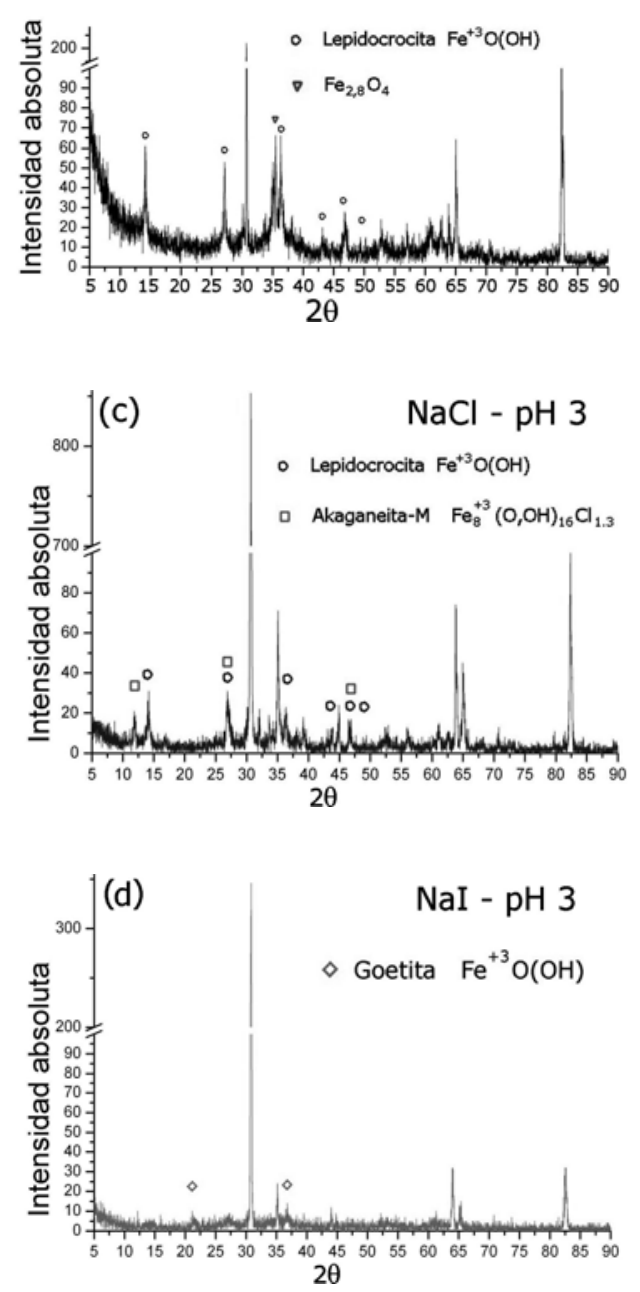
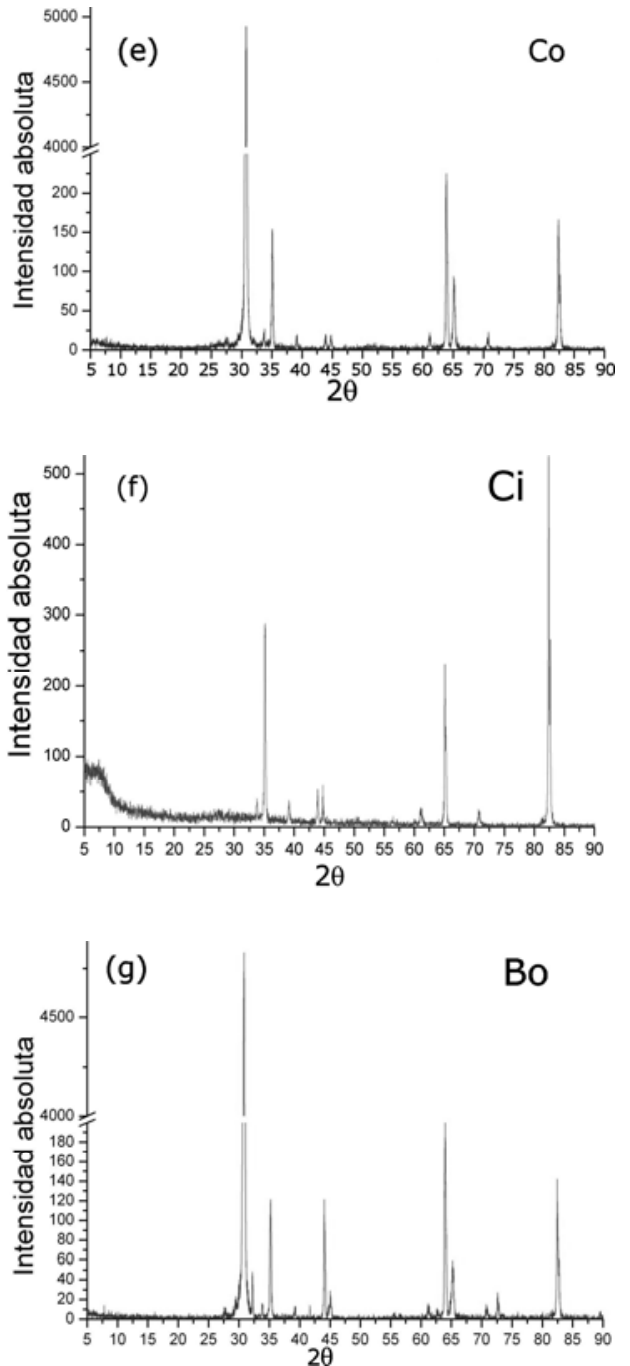

Fig. 3: Espectros XRD de distintas muestras. 
Las muestras expuestas a la solución de $\mathrm{NaBr}, \mathrm{pH}=3$ (Fig. 3b), presentaron productos de corrosión tales como Lepidocrocita $(\mathrm{FeO}-\mathrm{OH})$ y magnetita no estequiométrica, $\mathrm{Fe}_{2,9} \mathrm{O}_{4}$. La imagen SEM de dichas muestras reveló la presencia de gran cantidad de productos de corrosión, cuyo espectro EDXS detectó la presencia de $\mathrm{Fe}, \mathrm{O}$ y algo de $\mathrm{Br}$ (Fig. 4). La imagen SEM de una muestra expuesta a la solución de $\mathrm{NaBr}, \mathrm{pH}=8$ reveló una morfología de productos de corrosión en forma de placas superpuestas, sobre las cuales crecieron otros productos de forma esférica. El análisis EDXS de dichos productos mostró la presencia de $\mathrm{Fe} \mathrm{y} \mathrm{O}$ en las placas y de $\mathrm{Fe}, \mathrm{O}$ y $\mathrm{Br}$ en las esferas (Fig. 5)

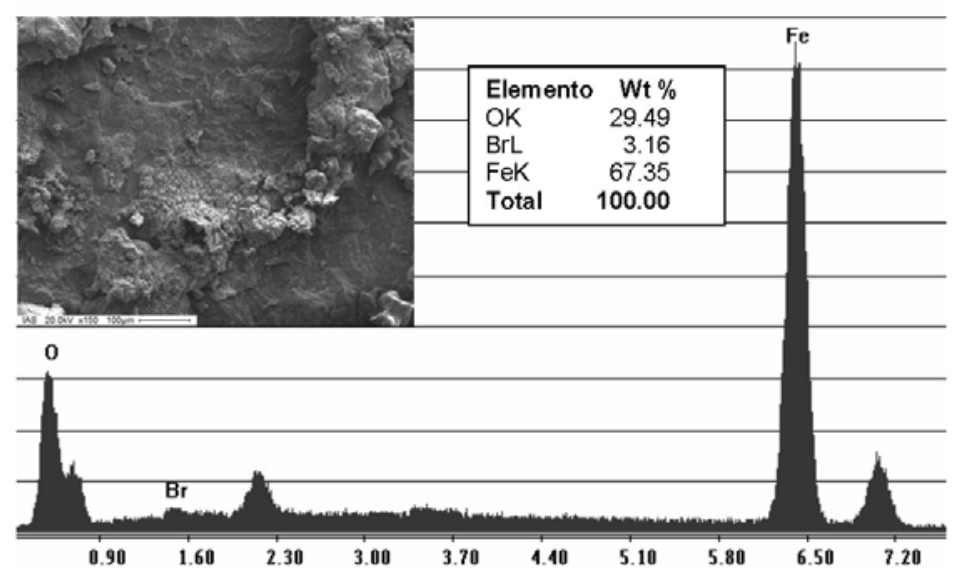

Fig. 4: Análisis SEM-EDXS de muestra $\mathrm{Br}, \mathrm{pH}=3$.
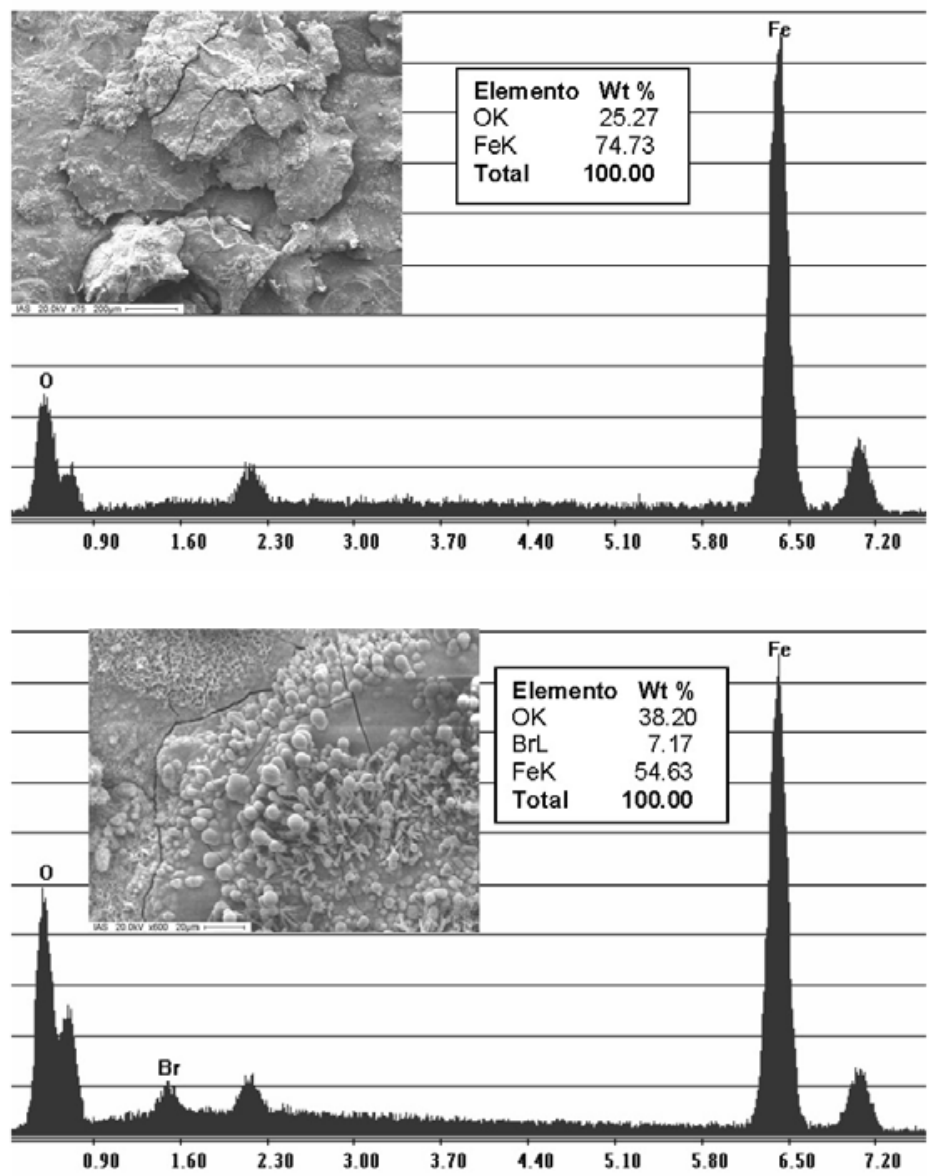

Fig. 5: Análisis SEM-EDXS de muestra $\mathrm{Br}, \mathrm{pH}=8$. 
Los espectros XRD de los productos de corrosión de las chapas expuestas a la solución de $\mathrm{NaCl}$ $(\mathrm{pH}=3)$ demostraron la presencia de Lepidocrocita y Akaganeíta-M, $\mathrm{Fe}_{8}(\mathrm{O}-\mathrm{OH})_{16} \mathrm{Cl}_{1.3}(\mathrm{Fig}$. 3c). La imagen SEM de una de esas muestras permitió observar la existencia de zonas claras con pocos productos de corrosión, y de zonas oscuras con productos de corrosión más voluminosos. El espectro EDXS de la zona clara detectó la presencia de $\mathrm{Fe}$, Sn y O, mientras que la zona oscura presentaba un contenido mucho menor de Sn y algo de Cl (Fig. 6). Los productos de corrosión de muestras expuestas a la solución de $\mathrm{NaCl}, \mathrm{pH}=8$, eran voluminosos y de aspecto esponjoso (Fig. 7). El espectro EDXS determinó una composición similar a la de la zona oscura de la muestra tratada en la solución con $\mathrm{pH}=3$. Los espectros XRD de las muestras expuestas a la solución Nal, $\mathrm{pH}=3$ (Fig. $3 \mathrm{~d}$ ), indicaron la presencia de Goethita (FeO-OH) como principal producto de corrosión, aunque la intensidad de sus picos era muy baja. La imagen SEM reveló productos de corrosión voluminosos con dos morfologías diferentes, una zona en la que es esponjosa y otra conformada por pequeñas esferas (Fig. 8). Los espectros EDXS sólo reflejaron la presencia de Fe y O. El contenido de $\mathrm{O}$ era mayor en los óxidos con morfología esférica que en los esponjosos.

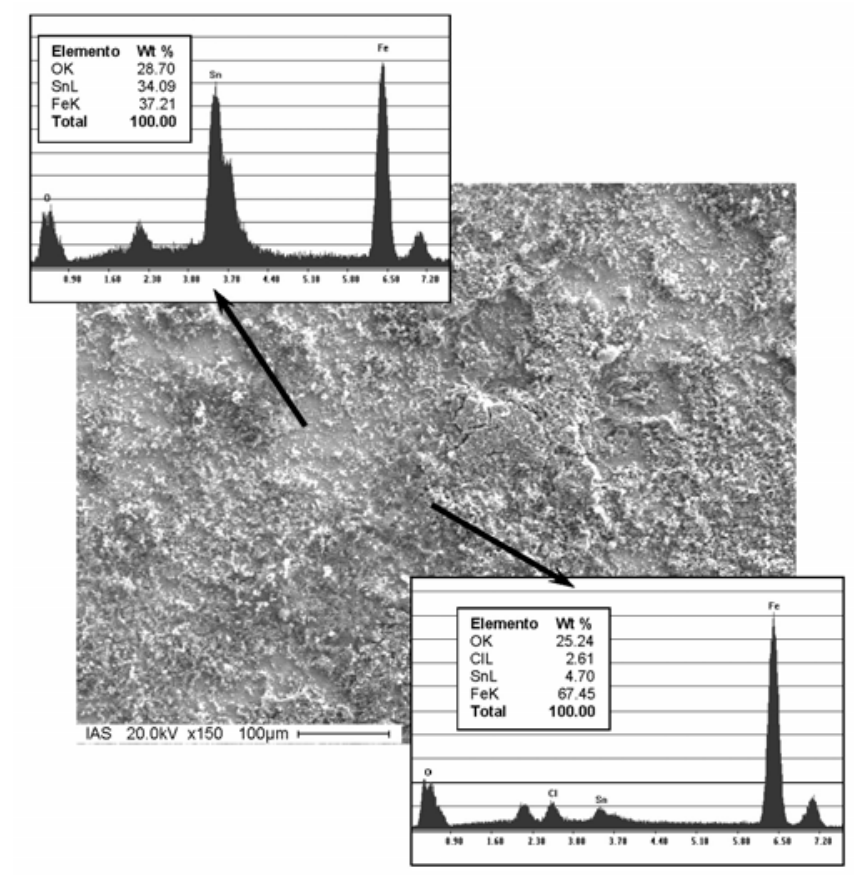

Fig. 6: Análisis SEM-EDXS de muestra $\mathrm{Cl}, \mathrm{pH}=3$.

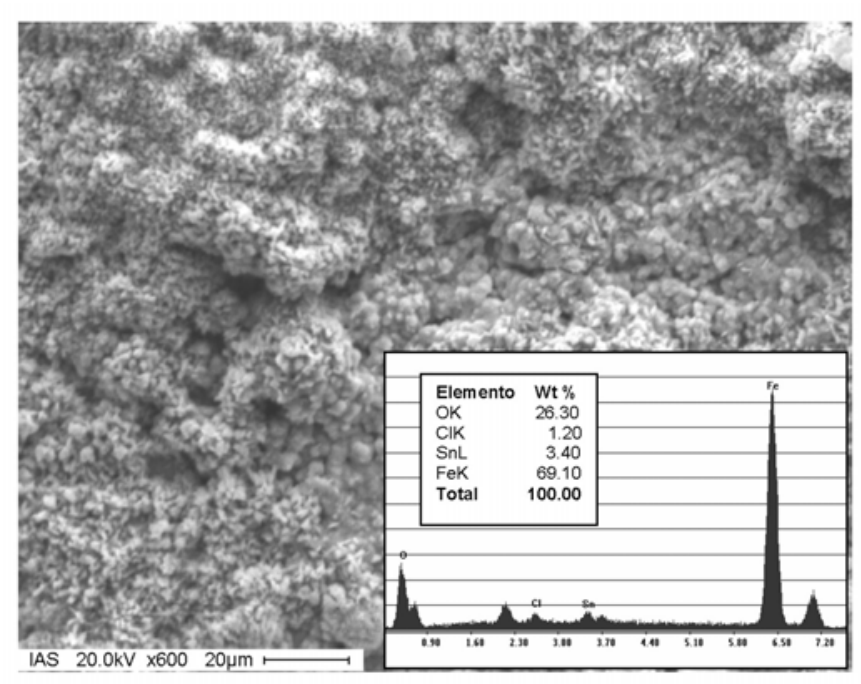

Fig. 7: Análisis SEM-EDXS de muestra $\mathrm{Cl}, \mathrm{pH}=8$. 
La superficie de las muestras en contacto con solución de $\mathrm{Nal}(\mathrm{pH}=8)$ presentó un aspecto similar a las obtenidas a $\mathrm{pH}=3$. Los espectros $\mathrm{XRD}$ de las muestras tratadas con solución de Co, Fig. 3d, fueron similares a los de la muestra testigo, salvo la menor intensidad de los picos de $\mathrm{Sn}$ y FeSn $\mathrm{Sn}_{2}$ la presencia de unos picos de óxidos de estaño con muy baja intensidad. La imagen SEM de estas muestras presentó una superficie con muy pocos productos de corrosión y, además, zonas claras y oscuras cuyos espectros EDXS revelaron un alto contenido de $\mathrm{Sn}$ en las zonas claras y menor en las oscuras (Fig. 9). El análisis SEM-EDXS de la muestra sometida a estudios de impedancia electroquímica en solución de Ci reveló la presencia de una película agrietada con alto contenido de $\mathrm{Na}$ (Fig. 10). El análisis EDXS debajo de la película, realizado a través de una grieta, reveló la presencia de mucho menos $\mathrm{Na}$ y $\mathrm{O}$ (Fig. 3f).

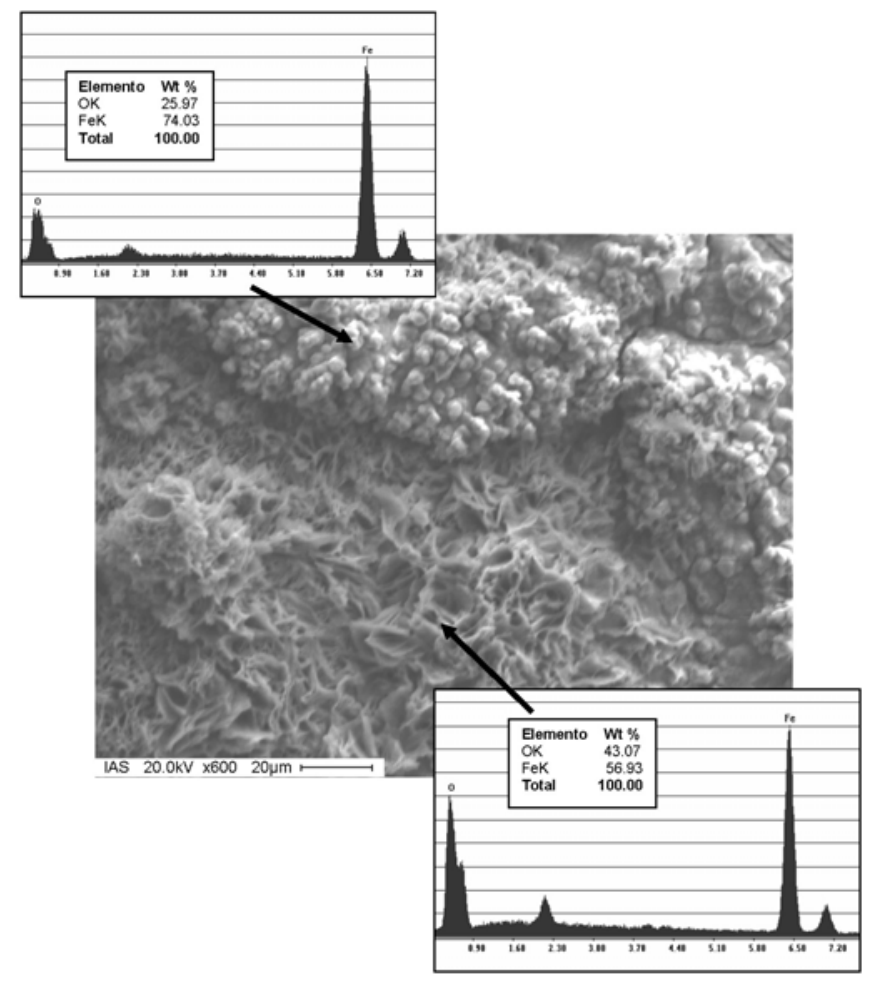

Fig. 8: Análisis SEM-EDXS de una muestra lo, $\mathrm{pH}=3$.

Las muestras sometidas a estudios de impedancia electroquímica en solución Bo sólo presentaron un ligero ennegrecimiento de la superficie a partir del primer día de tratamiento. Los espectros XRD, Fig. $3 g$, resultaron similares a los de la muestra testigo, aunque con una disminución de la intensidad correspondiente a los planos $\{100\}$.

\section{Medidas electroquímicas}

\section{a) Curvas de polarización potenciodinámica}

Antes de comenzar a discutir los resultados derivados de aplicar estas técnicas es menester enfatizar que los mismos fueron obtenidos usando hojalata desnuda y no reflejan la performance de la hojalata pintada. Etapa a la que se llegará oportunamente. Por su agresividad hacia el sustrato metálico, la acidez y el tipo de ácido que conforman el electrolito en contacto con la hojalata son dos de los factores que más contribuyen a facilitar la corrosión de ese metal. Esta última es también afectada en la misma dirección por la presencia de oxígeno y/u otra sustancia oxidante capaz de proveer la necesaria reacción catódica complementaria (Larburu, 1996; Zumelzu y Cabezas, 2001). En términos generales, el proceso de corrosión comienza con la disolución de la capa de pasivación provista por el cromo y destinada a proteger superficialmente a la hojalata, esto deja a la vista la capa de estaño de color más gris. Inicialmente, el ataque tiene lugar en áreas localizadas cuya magnitud depende no sólo de la cantidad de defectos o heterogeneidades de la capa más externa sino también de la resistencia del acero base y de la capa del intermetálico $\mathrm{FeSn}_{2}$. 
La respuesta al barrido potenciodinámico obtenida en cada electrolito usado sin modificar el valor de su $\mathrm{pH}$ original ilustra la Fig. 11. La simple observación visual de las curvas permite determinar la existencia del importante efecto que la composición salina del electrolito ejerce sobre las ramas anódicas y catódicas de las curvas de polarización y, por ende, sobre los valores del potencial y de la velocidad de corrosión de la hojalata ensayada. Con el propósito de cuantificar de la forma más objetiva posible estos efectos y luego realizar un análisis comparativo de los mismos, los datos experimentales fueron ajustados en el intervalo de potencial $\pm 0,12 \mathrm{~V}$ a partir del PCA, utilizando las rutinas de cálculo del programa CorrView®.

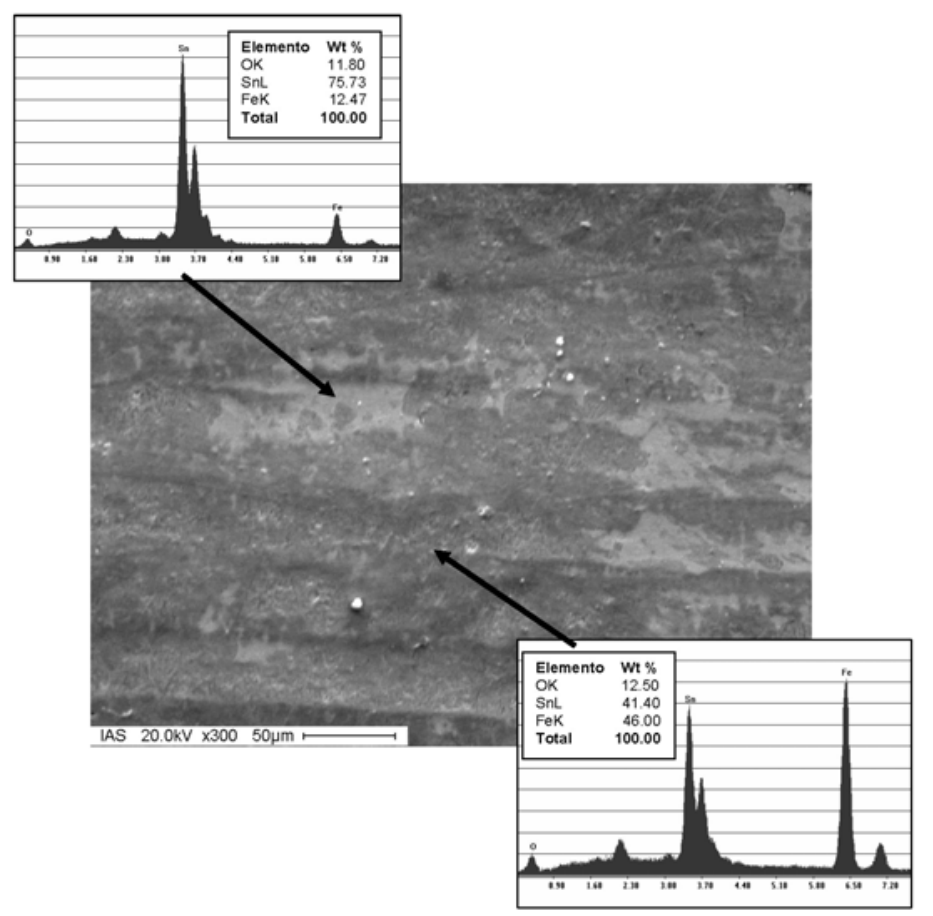

Fig. 9: Análisis SEM-EDXS de muestra Co.

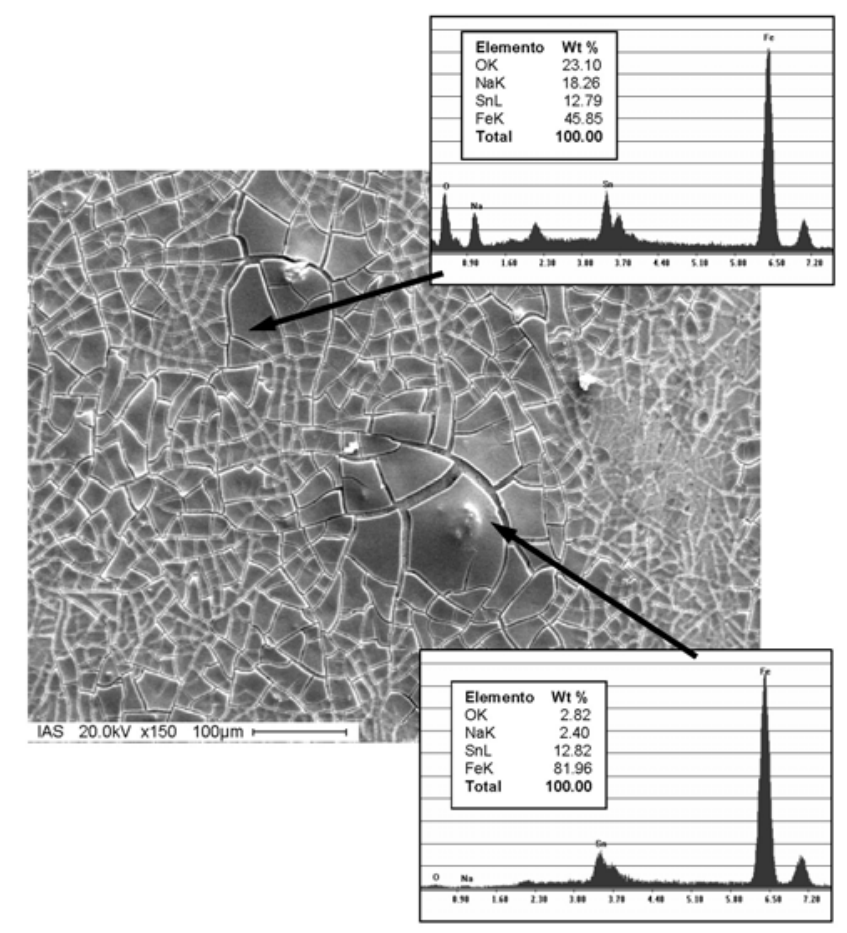

Fig. 10: Análisis SEM-EDXS de muestra Ci. 
Resumidos por razones de espacio a solo el valor de pH original para cada solución, en la Fig. 12 puede ser visto que los resultados derivados de aplicar el mencionado proceso de cálculo a las curvas experimentales permiten establecer el siguiente ordenamiento en función de su agresividad hacia la hojalata: $\mathrm{Ci}>\mathrm{Co}>\mathrm{Bo} \approx \mathrm{Cl} \approx \mathrm{Br} \approx$ lo. Los datos revelan que, en relación con lo acontecido en las soluciones "buffer", los iones haluros facilitan menos la disolución activa de la capa metálica. Este comportamiento se asocia con una mayor habilidad de esos iones para adsorberse y bloquear los sitios activos a causa de su menor radio iónico. Un estudio similar al anterior, aunque en este caso destinado a cuantificar la dependencia de la corrosión de la hojalata con el pH de las distintas soluciones de halogenuros aportó la información mostrada en la Fig. 13.

En esta última puede verse que la dispersión en los valores de densidad de corriente de corrosión, parámetro directamente asociado con la velocidad de corrosión del sustrato metálico, es muy importante alcanzando en algunos ensayos dos o más órdenes de magnitud. La existencia de tal dispersión es común cuando los materiales sometidos a ensayo provienen de líneas industriales continuas de fabricación ya que, en tal condición, no sólo exhiben una gran heterogeneidad en la composición química y estructural sino también en el delgado espesor $(<1 \mu \mathrm{m})$ de la superficie protectora más externa en contacto directo con el medio. No obstante esto, queda demostrado que resulta posible inferir una mayor tendencia a la degradación a medida que se incrementa la acidez del medio.

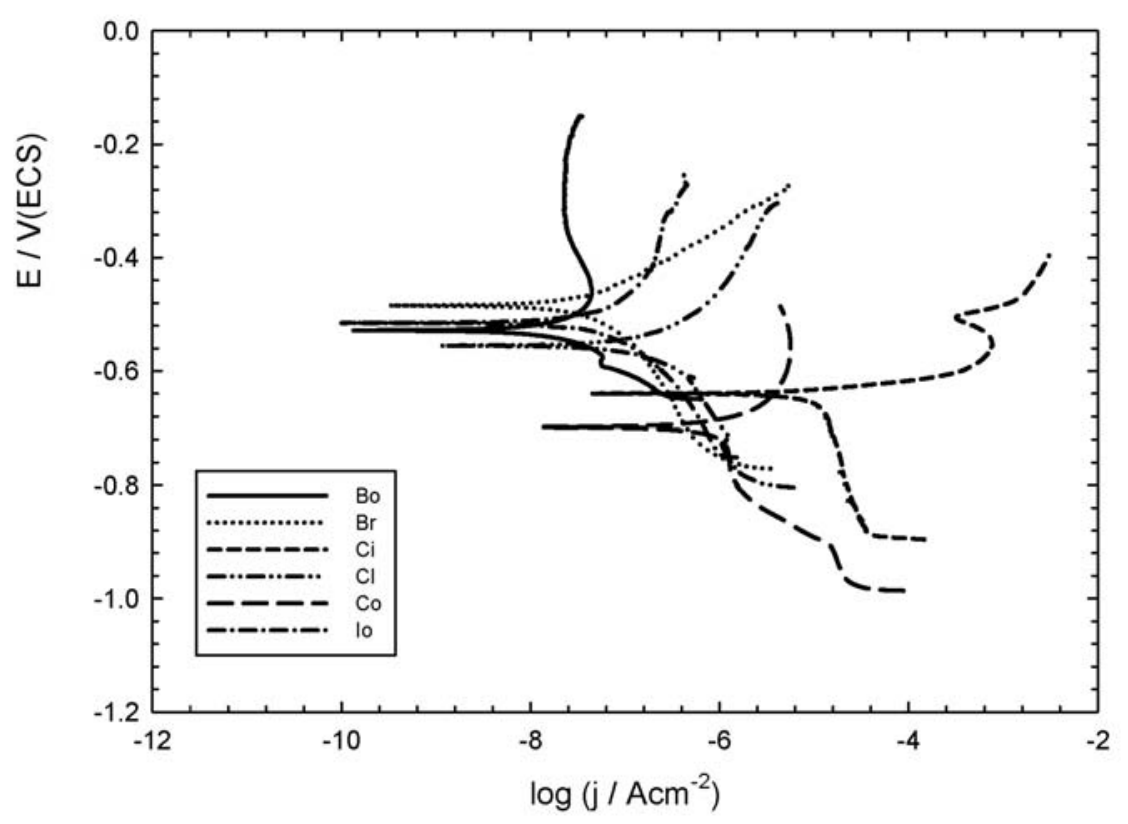

Fig. 11: Curvas potencial / densidad de corriente.

\section{b) Ensayos de impedancia electroquímica}

Con el fin de entender mejor el efecto de la composición del electrolito sobre el comportamiento de la hojalata fueron llevadas a cabo medidas de impedancia en función del tiempo de inmersión. Los datos experimentales así obtenidos fueron graficados en diagramas de Bode (módulo y ángulo de fase vs. frecuencia), Fig. 14.

En ella puede ser visto que el cambio más importante en el valor del módulo de impedancia (|Z|) ocurre dentro del primer día de inmersión, durante el cual decreció hasta dos órdenes de magnitud. Por su lado, el ángulo de fase, parámetro más sensible a la dispersión en función de la frecuencia, exhibe significativas modificaciones sólo a $\mathrm{pH}=3$. Esto es indicativo de la existencia de continuos cambios en la cinética y mecanismos de los procesos superficiales a causa de la fuerte acidez del electrolito. También lo es la aparición de más de dos constantes de tiempo. 


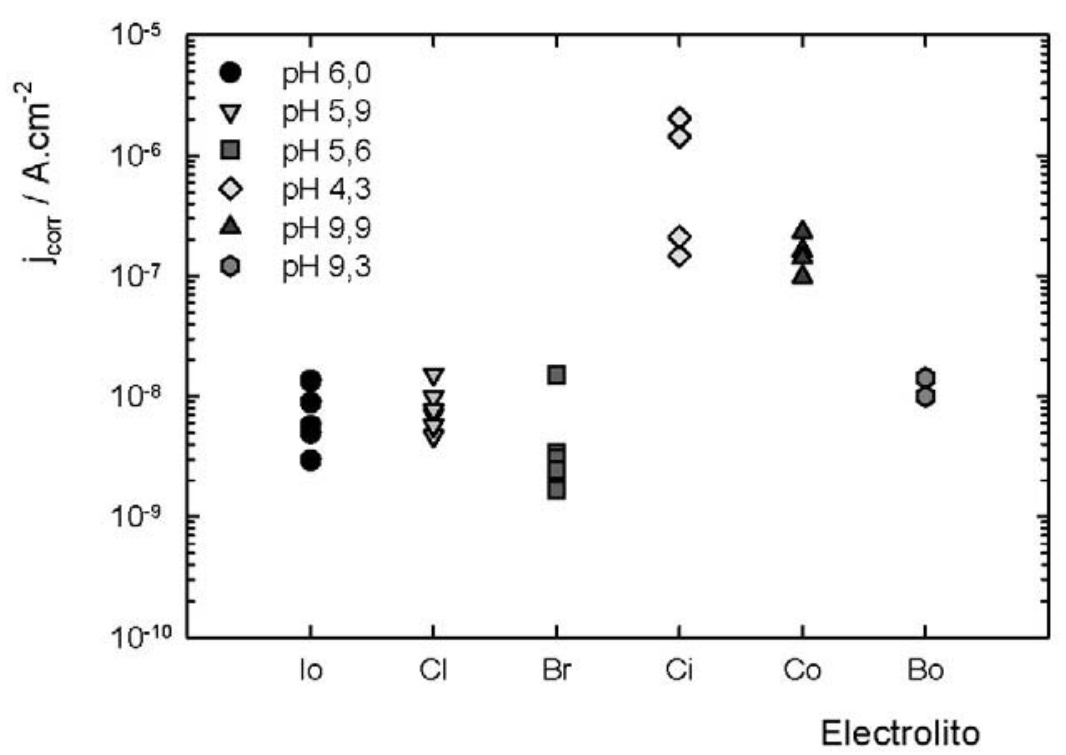

Fig. 12: Distribución de velocidad de corrosión en cada electrolito a su pH original.

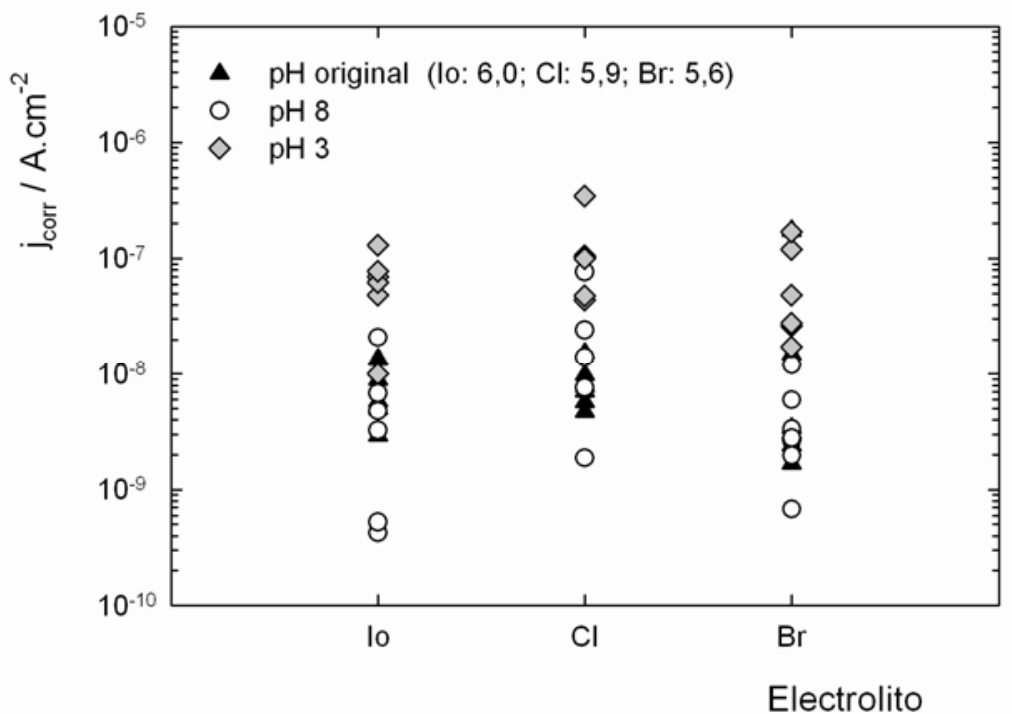

Fig. 13: Influencia del pH sobre la distribución de velocidades de corrosión.

Por su parte, los diagramas de Bode de la Fig. 15 corresponden a réplicas de la chapa de hojalata en contacto con las soluciones "buffer". Excepto las muestras sumergidas en Bo, las restantes presentaron un decrecimiento del módulo de impedancia a tan solo $24 \mathrm{~h}$ de exposición pero luego este parámetro permaneció prácticamente constante. Además, y con la misma excepción, dicho comportamiento estuvo reflejado con la aparición de al menos dos constantes de tiempo dentro del primer día de inmersión. Los ensayos realizados al PCA y en condiciones de inmersión permanente en cada electrolito mostraron, al comienzo de los mismos, una cinética de deterioro mucho más rápida en las soluciones de halogenuro y en el "buffer" Ci. Este factor condujo a la interrupción del ensayo a los cuatro días de exposición, en cambio, en Co y Bo se los dio por finalizados a los 30 días. Esta diferencia de comportamiento frente a la corrosión puede ser atribuida al efecto barrera generado por los productos de corrosión formados en cada caso. Así, en $\mathrm{Cl}, \mathrm{Br}$ e lo fue encontrada una tendencia a disminuir la velocidad de corrosión con el aumento del pH. Esto fue atribuido no solo a la posibilidad de adsorción de estos iones en sitios activos del metal sino también a la morfología y distribución de los productos de corrosión sobre la superficie.

Con respecto al comportamiento en medios "buffer", el peor se obtuvo en el Ci debido a la capacidad que tienen estos aniones de complejar el estaño, favoreciendo el proceso de desestañado (Zumelzu 
y Cabezas, 2001). Por otro lado, y en concordancia con los estudios de superficie descriptos más arriba y comparados con la muestra testigo, el encontrado en Co y Bo demostró que el contacto con estos electrolitos condujo a un menor ataque de la superficie, particularmente en el caso del Bo.
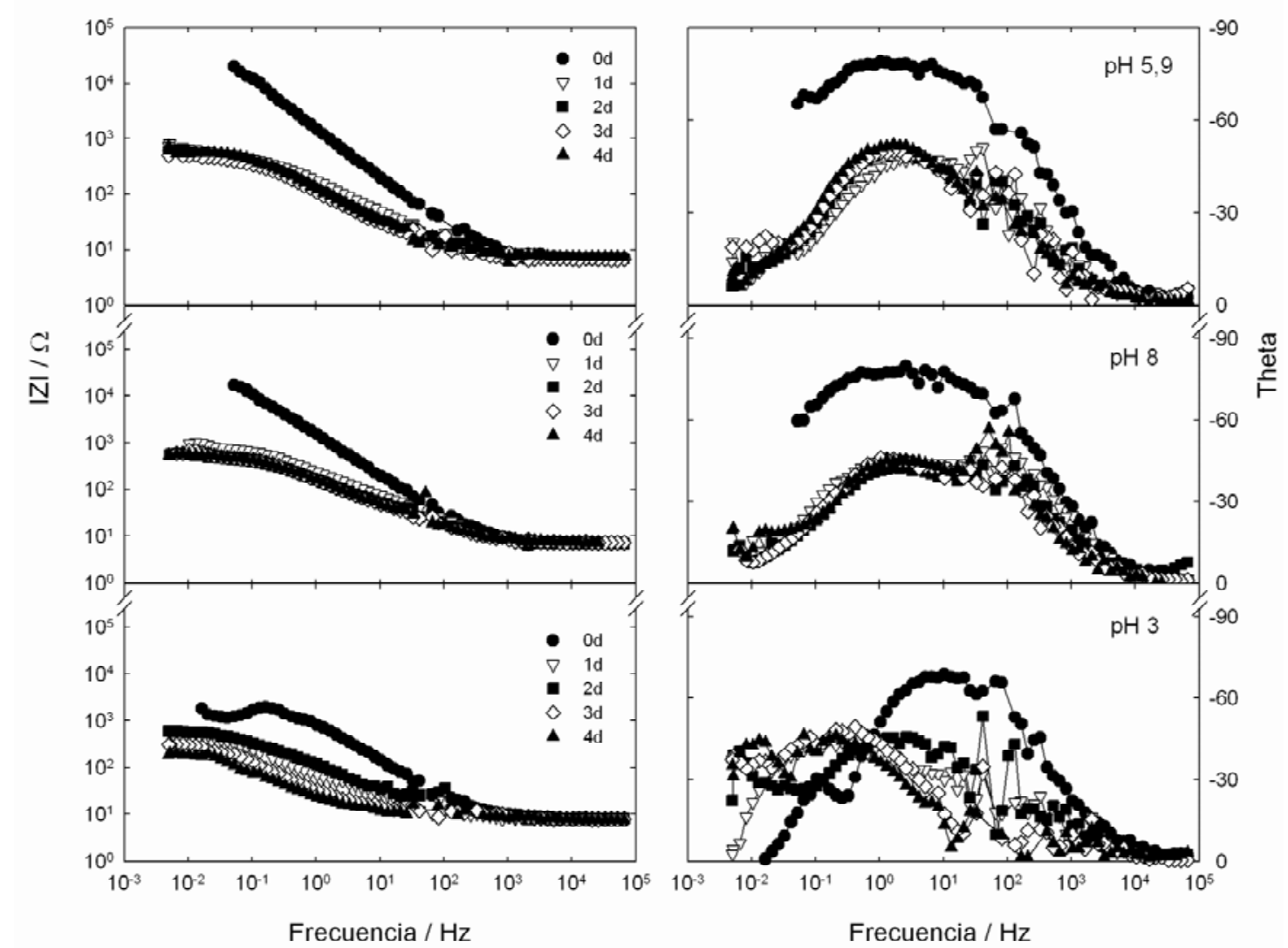

Fig. 14: Diagramas de Bode de hojalata en contacto con soluciones 0,05M de $\mathrm{NaCl}$.
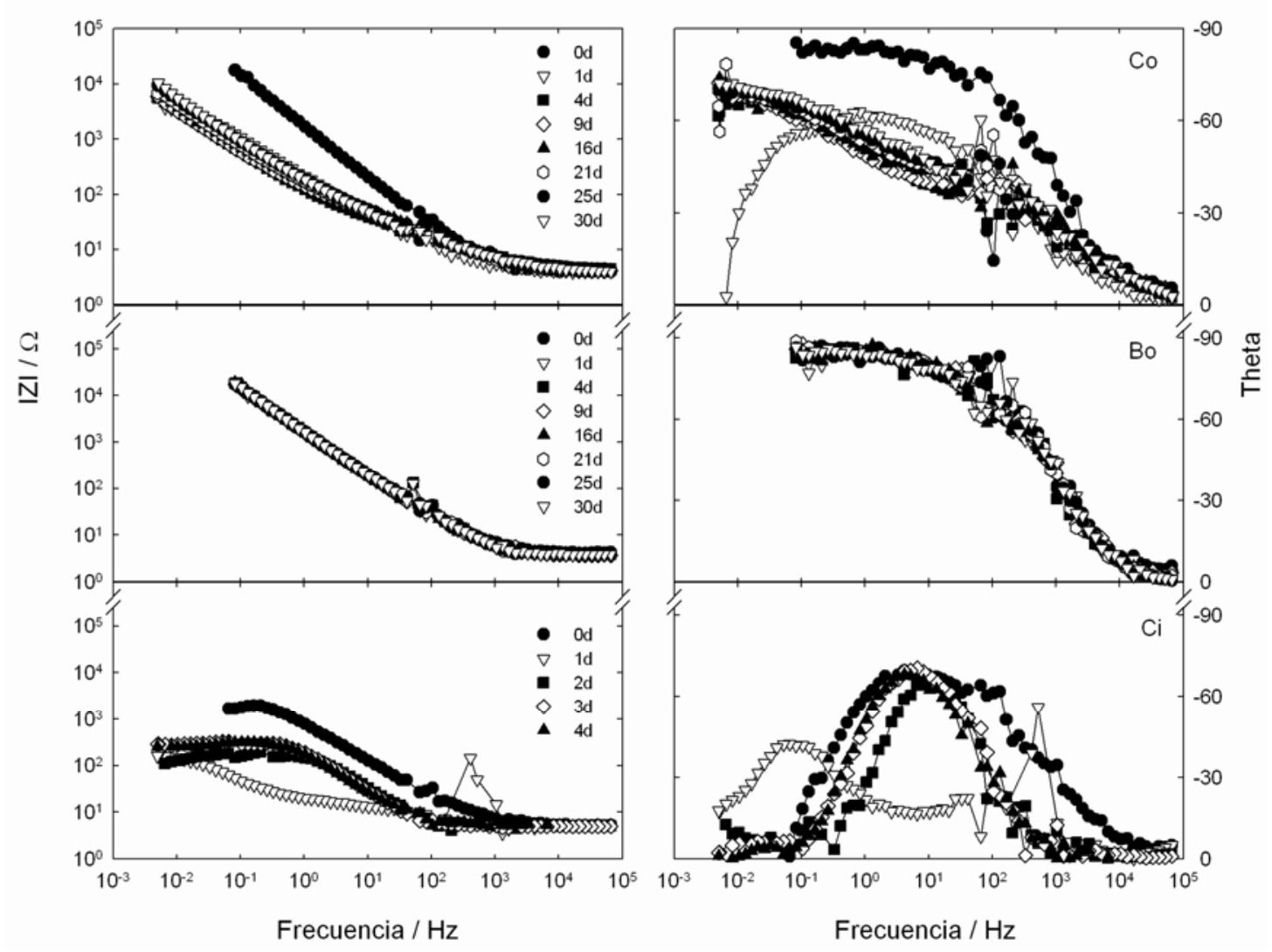

Fig. 15: Diagramas de Bode de hojalata en contacto con las soluciones "buffer" Co, Bo o Ci. 


\section{CONCLUSIONES}

Del análisis de la totalidad de los resultados experimentales puede inferirse que:

1.- En todas las soluciones los cambios superficiales más significativos se produjeron durante las primeras $24 \mathrm{~h}$ de exposición.

2.- La composición y morfología de los productos de corrosión formados dependió del medio con el cual el sustrato estuvo en contacto. En general, se trata de distintas variantes de un oxihidróxido de hierro, excepto en los casos de Bo y Co, donde los escasos productos de corrosión formados aportaron un efecto protector.

3.- Estos resultados son coincidentes con las velocidades de corrosión determinadas por técnicas electroquímicas y la mayor vida útil del recubrimiento en los ensayos de impedancia electroquímica.

\section{AGRADECIMIENTOS}

A la Comisión de Investigaciones Científicas de la Provincia de Buenos Aires (CIC), al Consejo Nacional de Investigaciones Científicas y Técnicas (CONICET) y a la Universidad Nacional de La Plata (UNLP) por el apoyo económico brindado para su ejecución.

\section{REFERENCIAS}

Barilli, F., R. Fragni, S. Gelati y A. Montanari, Study on the adhesion of different types of lacquers in food packaging, Prog. Org. Coat.: 46, 91-96 (2003).

Bastidas, J.M., J.M. Cabañes y R. Catalá; Effect of passivation treatment and storing on adhesion and protective properties of lacquered tinplate cans, J. Coat. Technol.: 69(871), 67-71 (1997).

Blunden S. y T. Wallace; Tin in cannaed food: a review and understanding of occurrence and effect, Food Chem. Tox.: 41, 1651-1662 (2003).

Boukamp, B.A.; “Equivalent Circuit”, Report CT88/265/128, CT89/214/128, University of Twente, The Netherlands, (1989).

Calderón, J.A. y C.P. Buitrago; Assessment of the susceptibility of lacquered tinplate cans to corrosion in different solutions using electrochemical techniques, Rev. Fac. Ing. Univ. Antioquia: 42, 30-37 (2007).

Doherty, M. y J.M. Sykes; A quantitative study of blister growth on lacquered food cans by scanning acoustic microscopy, Corros. Sci.: 50, 2755-2772 (2008).

Huang, Q.X., L. Jiang y D. Li; Effect of black plate on corrosion resistance of T5 tinplate, J. Iron and Steel Research Intern.: 13(2), 59-64 (2006).

Larburu, J.I.; Revestimientos de Hojalata y TFS, CENIM, Editado por el Consejo Superior de Investigaciones Científicas, España, 309-328 (1996).

Montanari, A. y otros seis autores; External corrosion of tinplate as affected by cooling-water composition in the food preserving industry, Industria Conserve (Italy): 75(2), 195-202 (2000).

Mora, N. y otros cuatro autores; Corrosion protection properties of cerium layers formed on tinplate, Corros. Sci.: 46, 563-578 (2004).

Palmieri, A., A. Montanari y G. Fasanaro; De-tinning corrosion of cans filled with tomato products, Corr. Engineer. Sci. and Technol.: 39(3), 198-208 (2004). 
Popova, S.N., B.N. Popov, R.E. White y D. Drazic; Determination of corrosion properties of lacquered timplate in citrate solutions by $d c$ and ac electrochemical methods, Corrosion: 46, 1007-1014 (1990).

Reinprayoon D. y otros cuatro autores; An impedance study on the corrosion properties of lacquered tinplate cans in contact with tuna and mussels in pickled sauce, Corros. Sci.: 40(9), 1455-1467 (1998).

Toŝković, D., M.B. Rajković e I. vČirić; Corrosion of tin plate in brine solutions, Russian J. Appl. Chem.: 75 (11), 1808-1811 (2002).

Zumelzu, E. y C. Cabezas; Influence of tinplate structure on its electrochemical. perfomance in a citricitrate medium, J. of Scientific \& Industrial Research: 55, 274-276 (1996).

Zumelzu, E. y C. Cabezas; Desempeño de hojalatas de colada y recocido continuo en ambientes agresivos, Jornadas SAM-CONAMET-AAS 2001. Misiones-Argentina. 659-666 (2001). 